\title{
The Study on Maneuverability of Electric Propulsion All-Direction Vector Thrusting Ship Using Rudder Propeller
}

\author{
Tan Jiawan*, Zhao Teng, Sun Peng and Wang Zhixiang
}

Maritime College, Chongqing Jiaotong University, Chongqing, 400074, China

\begin{abstract}
This paper studied the maneuverability of the pure electric propulsion all-direction vector thrusting ship called "Century myth", which also is the first one of its kind in inland rivers in China. Abilities such as turning, stop, changing of course and course keeping are studied. The main research method is by test and comparison, the result shows that the maneuverability of this kind of ship is much better than traditional ships running in inland rivers currently due to its alldirection vector thrusting, and are more comfortable due to its electric propulsion. This kind of ship becomes the new trend of developing environmentally friendly green ships on inland rivers both for its excellent maneuverability and reduced emissions. At the same time, the result of this trial test also provides reliable and objective data for revision and evolution of the specification for inland river ships.
\end{abstract}

Keywords: Electric propulsion, All-direction propeller, Maneuverability, Trial test.

\section{INTRODUCTION}

With the progressive application of China's sustainable economic development strategy and the booming of Chang Jiang river communication, vessels navigating in Chang Jiang are becoming faster, larger and more specialized than ever before. At the same time, more rules and standards relating to energy saving, emission reduction, vibration and noise reduction are proposed. Green energy saving and environment friend vessels, such as electric propulsion ships like "Century myth", becomes the new standard of ship development in Chang Jiang. "Century myth", is the first electric propulsion all-direction vector thrusting and "steering oar one" propulsion vessel in Chang Jiang, its excellent maneuverability and reliability has been studied in this paper.

During the past decades, a lot of work has been done around ship maneuverability, such as researches done by XU Mingcai, etc. [1-6], ZOU Zaojian etc. reviewed the latest work that has been done in this filed [7]. Researches related to electric propulsion are also focused by many researchers, DUAN Xuxu studied the matching of main engine and rudder of electric propulsion ships [8]. SHAN Tiebing etc. researched the hydrodynamic performance of ships with four propellers and two rudders $[9,10]$.

However, researches related to ships such as "Century myth" of electric propulsion, and with vector thrusting alldirection rudder are less-known. For this reason, this paper mainly focus on the study of this kind of ships.

\section{THE TRIAL TEST OF CENTURY MYTH}

According to Chapter 9 Claus 9.1.1, Section 5 of the "Inland river ship inspection rules" (2011), the inland river ships during the operation shall be equipped with maneuverability handbook, which mainly contains maneuvering data from the vessel's trial test, the whole trial testing process must be monitored by the water traffic monitoring systems as illustrated in Fig. (1).

\subsection{The Main Parameters of the Ship}

The dimension and main parameters of the electric propulsion ship "Century myth" are listed in Table 1. Installation of all-direction rudder propeller is shown in Fig. (2).

Table 1. Typical parameters of "Century myth".

\begin{tabular}{|c|c|}
\hline Length & $\mathbf{1 4 1 . 8 m}$ \\
\hline \hline Length between perpendiculars & $132.0 \mathrm{~m}$ \\
\hline molded breadth & $19.0 \mathrm{~m}$ \\
\hline designed draft & $2.90 \mathrm{~m}$ \\
\hline design speed & $24 \mathrm{~km} / \mathrm{h}$ \\
\hline Main propulsion motor model and the Numbers & 4 \\
\hline rated power & $680 \mathrm{~kW}$ \\
\hline rated speed & $1000 \mathrm{rpm}$ \\
\hline Propeller type & Rudder Propeller \\
\hline Rudder propeller diameter & $1680 \mathrm{~mm}$ \\
\hline Rudder propeller blade number & 4 \\
\hline
\end{tabular}




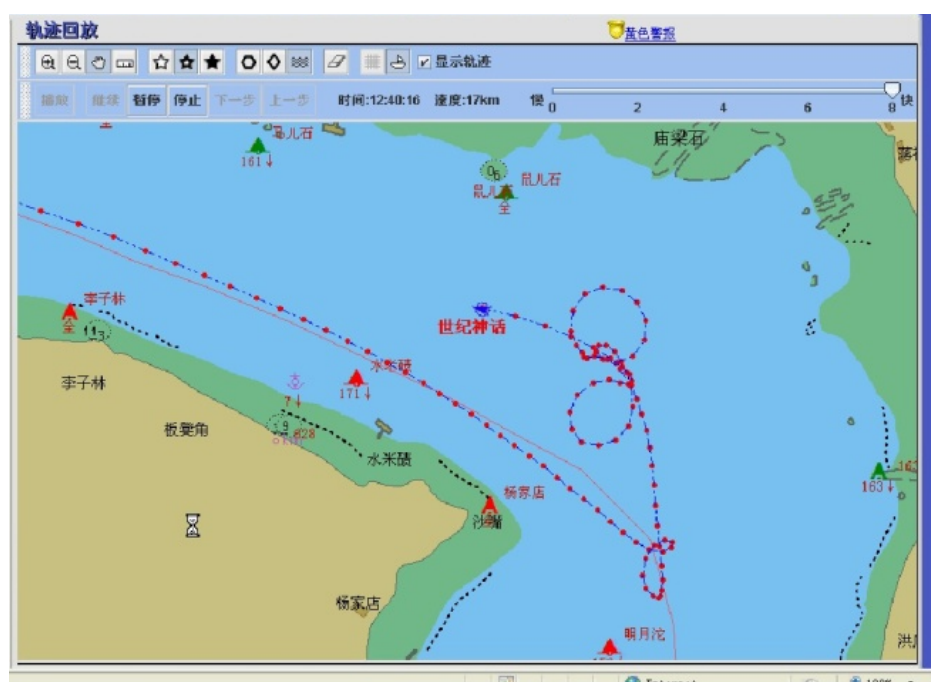

Fig. (1). Trial test result of the "Century myth ".

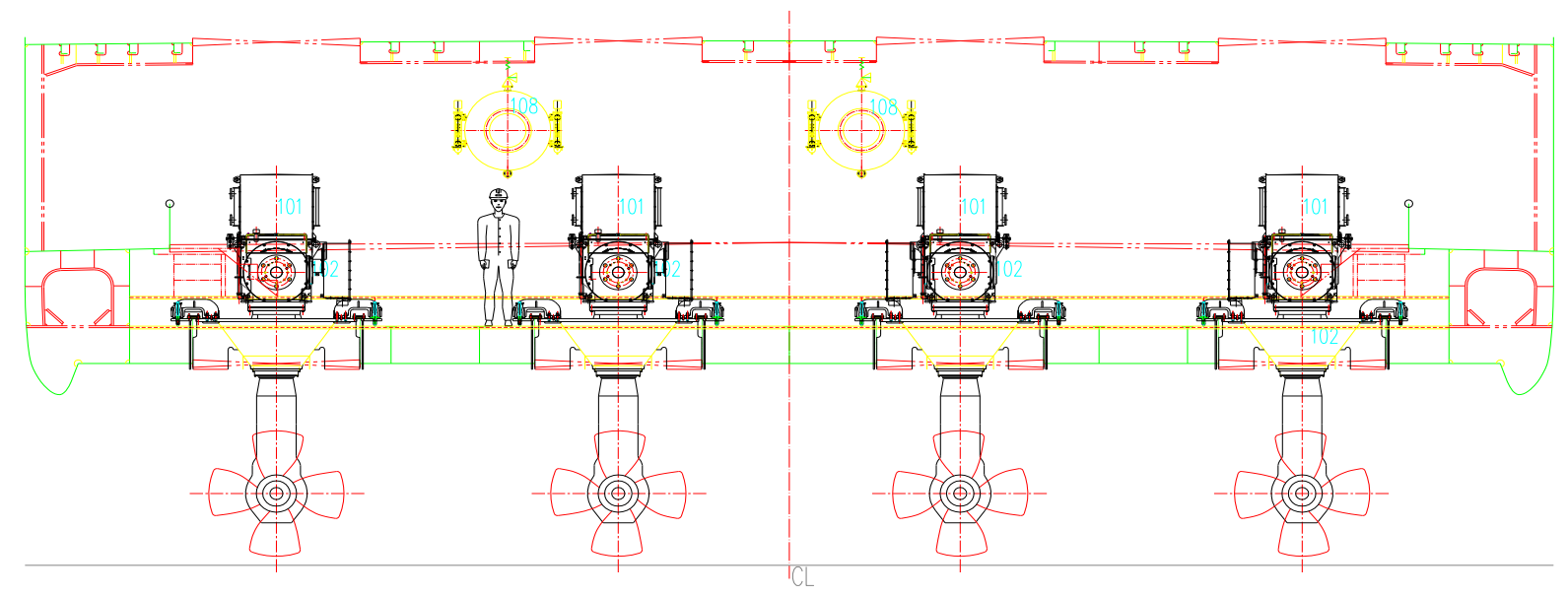

Fig. (2). Rudder propeller.

\subsection{Turing Ability Test}

The turning test is recorded by DGPS system, and the test is carried out in open water area with current speed of 1.2 $\mathrm{km} / \mathrm{h}$. The ship keeps constant speed and the rotation speed of the main engine is 955 RPM during turning. Turning test is carried out with left and right rudder angle of 90 respectively, each turning test stopped when the ship completed a circular turning with course turned up to $360^{\circ}$. Parameters such as transverse distance, longitudinal distance, the radius of gyration, diameter and maximum heeling angle are recorded for each turning test. Detailed results are shown in Table 2.

\subsection{Stop Ability Test}

Conditions for stopping test are the same as turning test. When the ship moves straight with full speed, changing the engine form "full ahead" to "stop", results in gradual speed reduction due to inertial force, which are recorded. Test results are shown in Table 3, the track of the test is illustrated in Fig. (3).

\subsection{Course Changing Test}

The test is started when the vessel is moving in the straight direction, with main engine at 955 RPM, then the ruder is turned to port/starboard for $15^{\circ}$ quickly and held at the new course until the course deviates to $15^{\circ}$ left (right) compared to the initial course. Then the rudder is turned in the opposite direction for $15^{\circ}$ (starboard / port $15^{\circ}$ ) and held there till the course deviates from the initial course to left ( right) $15^{\circ}$. The course is changed once again back to the left (right) $15^{\circ}$. The process is repeated three times. When the course coincides with the initial course, then the rudder is turned to $0^{\circ}$, while continuously recording the time, speed, course and rudder angle. The test results are plotted in Fig. (4).

\subsection{Course Stability Test}

The initial state is that the ship moves in straight with constant speed, with main engine at 955 RPM. Course stability test is done by keeping the rudder angle unchanged and maintaining course. The test time lasted 3 minutes for each case. The result is shown in Table 4 and Fig. (5). 
Table 2. Turning test results.

\begin{tabular}{|c|c|c|}
\hline Item & Turning by Hard a Port Rudder & Turning by Hard a Right Rudder \\
\hline engine speed $(\mathrm{r} / \mathrm{min})$ & 955 & 955 \\
\hline initial speed(km/h) & 15.2 & 12.3 \\
\hline initial course(Deg.) & 235 & 0 \\
\hline longitudinal distance $(\mathrm{m})$ & 0 & 0 \\
\hline maximum heeling angle(Deg.) & 1 & 1 \\
\hline Steady turning diameter(m) & 0 & 0 \\
\hline The ratio of tactical turning diameter to length(DT/L) & 0 & 0 \\
\hline \multirow{4}{*}{ The time needed for rotary Time needed for turning to course $(\mathrm{S})$} & $90 \mathrm{o}$ & 80 \\
\hline & $180 \mathrm{o}$ & 142 \\
\hline & $270 \mathrm{o}$ & 180 \\
\hline & $360 \mathrm{o}$ & 219 \\
\hline
\end{tabular}

Table 3. Stop test results.

\begin{tabular}{|c|c|c|}
\hline Item & \multicolumn{2}{|c|}{ Full Speed Ahead-stop } \\
\hline Main Engine Speed(r/min) & $\mathbf{1 0 0 0}$ & $\mathbf{0}$ \\
\hline The initial course(Deg.) & 24 \\
\hline Initial Speed(km/h) & 261.4 \\
\hline The final course(Deg.) & 2.3 \\
\hline Final Speed(km/h) & 594 \\
\hline Test time(s) & 1112 \\
\hline Trail distance(m) & 7.92 \\
\hline Ratio of track length to & \\
\hline the vessel's length & 1089 \\
\hline Experimental stopping distance(m) & 143 \\
\hline cc(m) & \\
\hline
\end{tabular}

Table 4. Test results of course stability.

\begin{tabular}{|c|c|c|}
\hline Item & $\begin{array}{c}\text { Keep Rudder Unchanged } \\
\text { (Maintain the Rudder Angle) }\end{array}$ & $\begin{array}{c}\text { Keep Course Unchanged } \\
\text { (Maintain the Course) }\end{array}$ \\
\hline \hline Main javascript:void(0);engine speed(r/min) & 1000 & 1000 \\
\hline Initial course (Deg.) & 27 & 27 \\
\hline
\end{tabular}


Table 4. contd...

\begin{tabular}{|c|c|c|}
\hline Item & $\begin{array}{c}\text { Keep Rudder Unchanged } \\
\text { (Maintain the Rudder Angle) }\end{array}$ & $\begin{array}{c}\text { Keep Course Unchanged } \\
\text { (Maintain the Course) }\end{array}$ \\
\hline \hline Initial Speed (km/h) & 24.6 & 24.2 \\
\hline The final course (Deg.) & 21.6 & 24.6 \\
\hline Final speed (km/h) & 24.8 & 180 \\
\hline Test time(s) & 180 & 2 \\
\hline Times of steering(n) & --- & 2 \\
\hline Steering frequency(c/m) & -- & 1 \\
\hline Maximum Angle of steering(Deg.) & -- & 1085 \\
\hline Experimental stroke(m) & 1030 & 19.8 \\
\hline The track's offset(m) & 23.5 & 2 \\
\hline
\end{tabular}

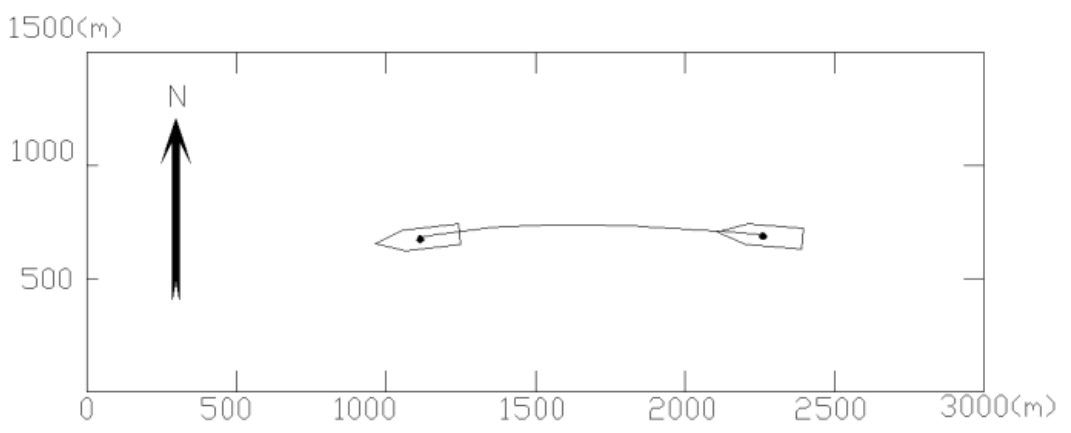

Fig. (3). Stop test track.

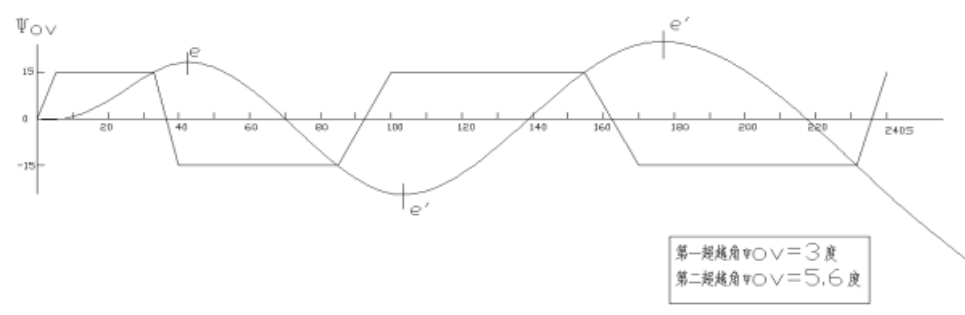

Fig. (4). $15^{\circ} / 15^{\circ} \mathrm{Zig}-\mathrm{Zag}$ test.

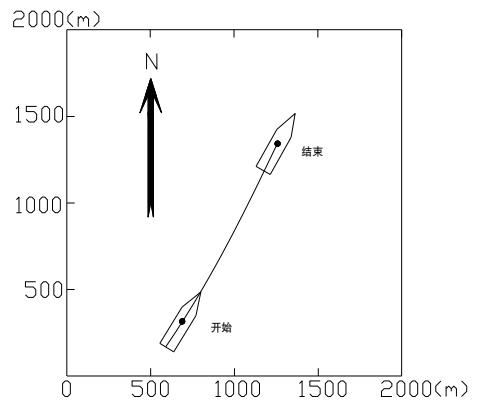

By fixed rudder angle

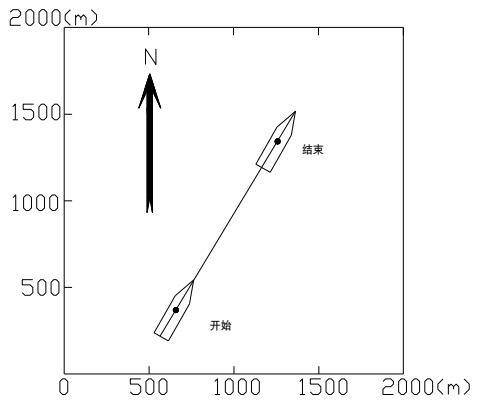

By fixed course

Fig. (5). Track of course stability test. 
Table 5. The approximate value of various type of ships' minimum relative diameter of turning.

\begin{tabular}{|c|c|c|c|}
\hline \multirow{2}{*}{ Type } & $\begin{array}{c}\text { The Minimum } \\
\text { Relative } \\
\text { Turning Diameter }\end{array}$ & Type & $\begin{array}{c}\text { The Minimum Relative } \\
\text { Turning Diameter }\end{array}$ \\
\hline \hline Destroyer & $5.0-7.0$ & Large passenger ship & $5.0-7.0$ \\
Large cargo ships & $5.0-6.5$ & Medium-sized passenger ship & $4.0-5.0$ \\
Medium-sized vessels & $4.0-5.0$ & Tanker & $3.5-7.5$ \\
General small boat & $2.0-3.0$ & & \\
\hline
\end{tabular}

Table 6. Test result of several typical ships.

\begin{tabular}{|c|c|c|c|c|}
\hline Jiang shen (passenger Ship) & ahead 280-0-astern 205 & 276 & 800 & 7.63 \\
\hline Lu ban (16000t multipurpose ship) & Ahead 137-0-astern 90 & 490 & 2408 & 16.61 \\
\hline
\end{tabular}

\section{ANALYSIS OF MANEUVERABILITY TEST RESULT}

\subsection{Analysis of Turning Ability Test Result}

In specifications related to ship designation, turning diameter of various types of ship is specified. For traditional propulsion and goodturning ability vessels, the relative smallest diameter is about $3 \mathrm{~m}$, meanwhile for poor tuning vessels, it is about $10 \mathrm{~m}$. Commonly for most vessels this figure falls into the range of 5 to $7 \mathrm{~m}$. The minimum relative turning diameters of most types of vessels are shown in Table 5 .

In Table 2, it shows that the longitudinal distance of "Century myth" is 0 , the horizontal distance is 0 , and initial turning diameter, tactical turning diameter, the ratio of tuning diameter to length all are 0 . All the parameters are not within those of traditional propulsion vessels, indicating that this vessel can turn in place without any positional movement, thus its turning ability is much better than that of traditional ships.

\subsection{Analysis of Stopping Ability Test Results}

The test results in Table 3 shows that the stopping ability of "Century myth" ship is much better than those of other similar ships such as "Lu ban" and "An Ping", etc. Table 6 listed some ships and their stopping abilities. The result shows that the stopping distance of "Century myth" is slightly larger than other smilar ships, and shorter than those of "Lu ban" and "An Ping", the track offset after stop is about $13 \%$ of the stopping distance.

\subsection{Analysis of Changing Course Ability Test Results}

Simple analysis of the zigzag test result can be done by analyzing the characteristics of the zigzag curve. Some typical parameters, such as overshoot angle and overshoot time (see Fig. 4) were considered for this work, and resulted in finding out $\mathrm{K}$ and $\mathrm{T}$ indices. This process is shown in Fig. (6).

The result of calculation shows that the turning ability index $\mathrm{K}$ and turning lag index $\mathrm{T}$ of "Century myth" ship are 0.435 and 0.135 respectively. It can be concluded that both turning ability and turning lag are satisfying. At the same time, the conformability, fast reaction to rudder, small turning circle are all better than traditional ships.

\subsection{Analysis of Course Keeping Ability Test Results}

To ensure the course keeping ability of "century myth", tuck plates were settled at the rear of the ship's keel. As shown in Table $\mathbf{4}$, the course stability test of "century myth" was conducted at full speed. And the result shows that after forward $1030 \mathrm{~m}$ at a constant rudder angle the track offset is $23.5 \mathrm{~m}$, track offset accounted for $2.3 \%$ to forward distance, track offset is $19.8 \mathrm{~m}$ after moving forward by $1085 \mathrm{~m}$ when the course is kept constant. Track offset accounts to about $1.8 \%$ of the forward distance, which means better course stability of this vessel.

\section{CONCLUSION}

Comparing the "century myth" electric propulsion trial tests and analysis, stop performance, course changing ability 


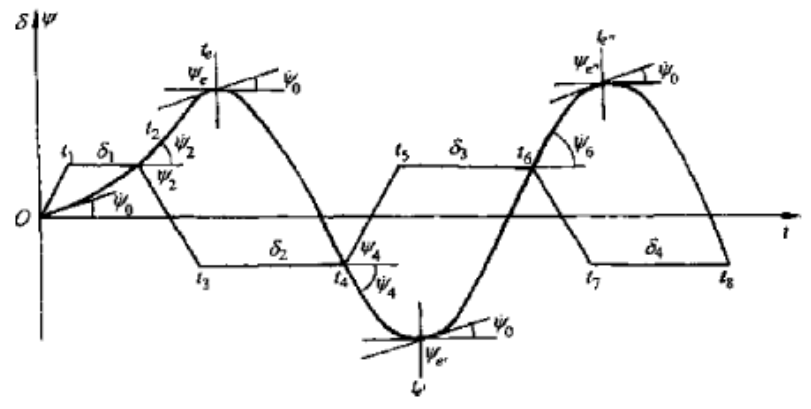

Fig. (6). Zigzag test analysis.

and course keeping ability with the traditional propulsion vessels, the result shows that the maneuverability of "century myth" is much better than that of traditional propulsion vessels. The "century myth" is energy efficient, has less vibrations and noise, it shall become the new trend of inland vessels.

\section{CONFLICT OF INTEREST}

The author confirms that this article content has no conflict of interest.

\section{ACKNOWLEDGEMENTS}

This paper is supported by Chongqing Science \& Technology Committee (cstc2012gg-yyjsB70002), and also thanks to Chongqing Dong Gang Ship building corporation for providing us the test environment and test result of "Century myth".

\section{REFERENCES}

[1] X. Mingcai, "Numerical Simulation of Maneuverability of Surface Warships", Harbin: Harbin Engineering University, 2011, pp. 1730

Received: November 26, 2014

Revised: January 08, 2015

Accepted: January 21, 2015

(C) Jiawan et al.; Licensee Bentham Open.

This is an open access article licensed under the terms of the Creative Commons Attribution Non-Commercial License (http://creativecommons.org/licenses/by-nc/3.0/) which permits unrestricted, non-commercial use, distribution and reproduction in any medium, provided the work is properly cited.
[2] I. Aoki, K. Kijima, Y. Furukawa, and Y. Nakiri, "On the prediction method for maneuvering of a full scale ship," Journal of The Society of Naval Architects of Japan, vol. 3, pp. 157-165, 2006. neuvering in waves," The Mechanics of Ship, vol. 4, no. 1, p. 15, 2000

[4] L. Dianpu, "The Ship Motion And Modeling”, Beijing: National Defense Industry Press, 2008, pp. 13-17.

[5] X. Zhongming, Modeling and Simulation of Ship Maneuvering Motion in waves, Dalian: Dalian Maritime University, 2007, pp. $15-32$.

[6] W. Xinqi, "Study on Ship Maneuvering Motion and Virtual Simulation Technology", Harbin: Harbin Engineering University, 2007, pp. 13-14.

[7] Z. Zaojian, Progress of research on ship maneuverability. Plenary meeting of academic committee of the sixth session of the mechanics of ship, Zhenjiang, 2006, pp. 54-57.

[8] D. Xuxu, Analysis of engine-propeller matching and economy of electric propulsion vessel, Engine and Propeller of Electrical Propulsion Ship and its economic Analysis. Dalian: Dalian Maritime University, 2008, pp. 3-5.

[9] S. Tiebing, "Hydrodynamic Performances of Four Propeller Twin Rudder Ship Under Different Working Conditions and its Maneuverability", Harbin: Harbin Engineering University, 2011, pp. 1-2.

[10] Q. Xinchuan, H. sheng, and C. Xin, "Study on the hydrodynamic interference system four paddle two rudders propulsion," China Shipbuilding, vol. 49, no. 1, p. 112, 2008.
[3] F. Sheming, "A comment on the calculation methods of ship ma- 